\title{
CONTRIBUTION TO THE HISTOPATHOLOGY OF "PSEUDOTUMOR CEREBRI"
}

PERCIVAL BAILEY, Ph.D., M.D.

Resident Physician, Neurological Service, Cook County Hospital

CHICAGo

\section{INTRODUCTION}

In 1904, Nonne ${ }^{1}$ reported a series of cases which he tried to combine into a clinical entity. This was characterized by a more or less chronic development of the picture of brain tumor, with or without localizing signs, and without discoverable etiology. The patients usually recovered, either spontaneously or after treatment with mercury and iodids. If death occurred, no adequate macroscopic or microscopic lesions could be found. Nonne went so far as to claim that in some cases no microscopic pathology was present.

Nonne's publication was followed by numerous reports of similar cases in some of which the symptom-complex in question was referred to as "die Nonnesche Krankheit" ${ }^{2}$ or "das neue Kranksheitsbild." ${ }^{3}$ Prior to Nonne, a number of similar cases were reported by Quincke ${ }^{4}$ under the name of serous meningitis.

It was well known that various pathologic conditions could simulate brain tumor, but the idea that at necropsy no pathologic changes or an unknown pathologic lesion might be found met with widespread skepticism. At the present time, such an opinion is practically abandoned, although Nonne in his last word on the subject ${ }^{5}$ still maintains that such cases exist.

As foundation for this opinion, there could be found in the literature only two cases: Case 11 in Nonne's ${ }^{1}$ series, and case 9 in Reichardt's. ${ }^{6}$ of these, Reichardt's bears clinically no resemblance to brain tumor,

* From the Surgical Service of Peter Bent Brigham Hospital, Boston, and from the Pathological Laboratories of Cook County and Psychopathic Hospitals, Chicago.

1. Nonne: Ueber Fälle vom Symptomenkomplex von Tumor cerebri mit Ausgang in Heilung, Deutsche Zeitschr. f. Nervenheilk. 27:169, 1904.

2. Oppenheim and Borchardt: Zur Meningitis serosa chronica circumscripta (cystica) des Gehirns, Deutsche med. Wochschr. 36:57, 1910.

3. Finkelnburg: Ueber Pseudotumor cerebri, Zentralbl. f. d. Grenzgebiete d. Med. u. Chir. 15:515, 1912.

4. Quincke: Ueber Meningitis serosa, Samml. klin. Vortr. 67:655, 1893 (Innere Med., no. 23).

5. Nonne: Der Pseudotumor cerebri, Neue Deutsche Chirurgie 10:107, 1914 (Die allgemeine Chirurgie der Gehirnkrankheiten, II Teil).

6. Reichardt: Zur Entstehung des Hirndrucks und anderer Hirnkrankheiten (u. s. w.), Deutsche Ztschr. f. Nervenheilk. 28:306, 1909. 
but was a straightforward case of catatonia. In Nonne's case, one cannot help feeling that if the microscopic examination, which was very inadequate, had been more thorough, some changes would have been found. Cases studied microscopically with care have always shown pathologic changes. Only six such examinations have been recorded and they will be briefly reviewed.

\section{REVIEW OF CASES WITH HISTOPATHOLOGIC REPORTS}

CASE 1. - A man, aged 20, gave a history of gradually developing frontal headache, with defective hearing on the right, defective vision, double vision and lethargy.

Findings.--Atrophy of the optic nerves was found, the sense of smell was absent, the right corneal and conjunctival reflexes were sluggish, there were hyperesthesia of the upper branch of the right trigeminal nerve, and tenderness to pressure in the right stboccipital region. Diagnosis: tumor of the posterior fossa.

Necropsy.-No macroscopic pathologic change was discovered. Microscopically, widespread leptomeningitis (not tuberculous or syphilitic) over the base of the brain, and perineuritis as well as interstitial neuritis of the optic, olfactory and right acoustic nerves were noted. There were no changes in the brain except slight perivascular infiltration in the pons and medulla. Some polymorphonuclear leukocytes were seen around the eighth nerve.

Finkelnburg ${ }^{7}$ intimates that this is the first time a case simulating brain tumor has been properly examined. The findings we accept, but certainly the clinical picture was stretched to make it a brain tumor.

CASES 2 AND 3.-In these cases, studied pathologically by Rosenthal, it is impossible to judge just how closely a tumor picture was simulated since the history and clinical examination are very incomplete.

Findings.-Stiffness of the neck, stupor, falling to the right, cerebellar gait, and optic neuritis were present in Case 2. Regarding Case 3, it is stated only that the disorder was of cerebellar nature with optic atrophy.

Necropsy.-Nissl's acute cell disease involved the cortex; there was an increase of lipoids in the ganglion cells; the glia cells were not much changed, those along the vessels contained much fat, and the blood vessels were much dilated; macrophages (Abräumzellen) with blood pigment were found; preameboid and ameboid glia cells were seen near the ventricles; there was an increase of subependymal glia fibers; the leptomeninges were slightly infiltrated with lymphocytes, blood pigment and greenish products of cell catabolism (Abbaustoffe).

The findings are those of lowgrade meningo-encephalitis with hemorrhages and reactive phenomena in the glia.

7. Finkelnburg and Eschbaum: Zur Kenntnis des sog. Pseudotumor cerebri mit anatomischen Befund, Deutsche Ztschr. f. Nervenheilk. 38:35, 1910.

8. Rosenthal: Histologische Befunde beim sog. Pseudotumor cerebri, Ztschr. f. d. gesamte Neurol. u. Psychiat. 7:163, 1911. 
CASE 4.-A 14 year old boy gave a history of gradually developing left-sided weakness, psychomotor dullness, occasional headaches and vomiting.

Findings.-Left-sided spastic hemiparesis, uncertain gait, and increasing stupor were noted.

Necropsy.-There were no macroscopic changes. Microscopically, there were found marked lymphocyte and plasma cell infiltration of the adventitial spaces, with hyperemia and occasional hemorrhages; numerous large nucleated epithelial cells; occasional fat granule bodies (Körnchenzellen) and rare giant cells, especially in Langhans' sense. These changes were found around the small blood vessels of the right internal capsule, the neighboring lenticular nucleus, the dorsolateral part of the pes pedunculi, both subthalamic regions, the white substance of both cerebellar hemispheres and the nucleus dentatus.

The clinical picture in this case is again not quite convincing. Choked disk is absent and there were no epileptic fits. Yamakawa, ${ }^{9}$ who recorded the foregoing case, came to the conclusion that the changes found belong to the category of atypical tuberculous connective tissue changes.

Nonne ${ }^{5}$ reported two further cases with histologic examination, in the first by Spielmeyer and the second by Ranke.

CASE 5.-A woman, aged 47, after a psychic trauma, had transitory attacks of vomiting and diarrhea, with pain in the left foot. Soon afterwards she had double vision and spots before the eyes. For eight months there was gradually lessening acuity of vision.

Findings.-The patient was able to distinguish only light and dark; the skull was somewhat tender to pressure over the forehead; bilateral high grade choked disk was observed.

Course.-Right decompression was performed, with resulting hernia cerebri and death.

Necropsy.-Spielmeyer found macroscopically greatly dilated ventricles. Microscopic examination revealed moderately widespread affection of the cortex with involvement of the white substance, without dependence of the affection on the blood vessels. In the cortex the fibers were badly damaged and often entirely absent over wide areas; the nerve cells showed many chronic changes, and a great increase of the glia cells (Trabantzellen). In the deeper layers of the cortex the glia fibers were greatly increased, but particularly in the white matter. The glia cells did not show the characteristics of glioma cells. They resembled those seen in secondary glia proliferation. The process involved especially the vicinity of the central fissure and the adjoining frontal region.

Spielmeyer stated (according to Nonne) that he knew of no sickness which could cause the changes found. It seems that they may be well explained by the operation, which resulted in a hernia of the brain, hemiplegia and other permanent organic lesions.

9. Yamakawa: Eine chronische disseminierte Encephalitis unter dem Bilde des sog. Pseudotumor cerebri, Mitt. a. d. med. Fakult. d. k. Univ. zu Tokyo 10:201, 1913 . 
CASE: 6.-For four weeks a 35 year old man had occasional spells of vomiting, and for some time headaches which grew worse at night. Later there were double vision and spots before the eyes.

Findings.-Definite but not high grade choked disk with hemorrhages was observed, the pupillary reactions to light were sluggish and slight, the blood Wassermann reaction was positive, the pressure of spinal fluid was high, with a cell count of 25 .

Necropsy.-Marked hydrocephalus internus and ependymitis granularis were present. Microscopic examination of the brain revealed cadaver changes (27 hours postmortem); infiltration of the pia with lymphocytes and an occasional mast cell; slight perivascular infiltration with lymphocytes and an occasional mast cell in the cortex, and very marked similar infiltration in the cerebellum, brain stem and basal ganglions; products of tissue catabolism (Abbauprodukte) in all regions, especially near the ventricles, where glia cells were present with homogeneous bodies containing lipoid material; widespread ependymal proliferation in all the ventricles; occasional fresh hemorrhages in the cortex, and proliferation of the intima cells without signs of fresh proliferation in many of of the blood vessels.

Ranke concluded that there was present a chronic inflammatory process, most probably syphilitic, with secondary hydrocephalus, and that the glia, ependymal and "Abbau" changes near the ventricles were probably secondary to the pressure of the ventricular fluid. From the clinical history one would rather have suspected that cerebral syphilis and not a tumor would have been found.

It will be noted from the foregoing reports, what would be even more evident if the histories of other cases not reviewed should be recorded, that full-fledged tumor pictures are rarely present. The localizing symptoms of tumor are usually very meager; choked disk is not very pronounced and often absent entirely.

\section{REPORT OF AUTHOR'S CASE}

The patient whose report follows presented a definite left cerebellar hemisphere syndrome and bilateral choked disk reaching from 3.5 to 4 diopters.

L. McN., a school girl, aged 16, was admitted to the Peter Bent Brigham Hospital (Surg. No. 11187), Sept. 19, 1919, complaining of vertigo, attacks of headaches and vomiting, poor vision, cross-eyes, weakness of left side, and instability in walking.

History.-The family history was negative. The patient's birth was normal. She was a little late in walking and her mother says that her head has always been rather large. She had diphtheria eight years ago and a mild attack of influenza last winter, but has never otherwise been seriously ill. She had no injuries and no operations. Catamenia was normal. Her habits were good.

Present Illness.-According to the patient's father, this began after an attack of influenza, November, 1918. While playing in church the notes became dim and she had a severe frontal headache which afterwards spread over the entire head, and she took to bed. The next day the headache was gone, but since then every week or so she had severe frontal headache afterwards passing 
over the entire head and lasting for a day or two. Later, these headaches localized in the back of the head, and the neck became sore at times. Her father noticed that when she had severe headache she staggered in walking and was apt to go to the left, and that she could not use her left arm and leg so well as the right. The patient, however, says that she had these headaches for several months before the attack of influenza, though never so severe. The father noticed that her left eye was turned in last March, but the patient's aunt said that the eye had been crossed for some time previously; just how long is not certain. About two weeks before admission, after an interval of freedom from headaches for three weeks, lumbar puncture was performed. This caused very severe headache which has never been entirely relieved and was made worse by assuming the erect posture, so that the patient has not been out of bed since. She was not so alert as formerly and at the time of examination was very stupid. Dr. Barrett of the Charles Sanitarium made a Wassermann test of the blood and spinal fluid, which gave negative results.

Physical Examination:-The patient was well developed and well nourished. Her brow was furrowed, she moaned from time to time as though in great pain, and also yawned occasionally, and rubbed her nose. The head seemed rather large and square, but there was no cracked-pot sound. There was suboccipital tenderness on both sides, perhaps greater on the left. No dilatation of the extracranial veins or exophthalmos was present. Neck, heart and abdomen exploration proved negative. The blood pressure was 108 systolic and 58 diastolic. The skin and temperature were normal.

Cranial Nerves.-Olfactory: Odors were recognized, and there were no subjective odors.

Optic: Fundus examination revealed on both sides that the disk margins were obscure, the disk being elevated about 1 diopter. The physiologic cup was filled, the veins were slightly engorged, and there was slight perivascular streaking, but no hemorrhages. There was bilateral choked disk, but no hemianopsia to rough test.

Motor Oculi, Patheticus and Abducens: There was downward and outward squint of the right eye with ptosis of the right eyelid. The pupils were equal and regular and reacted to light but not to accommodation. Movements of the right eyeball were restricted inward and upward. There was no nystagmus.

Trigeminal: No involvement of this nerve was manifested.

Facial: This nerve was normal.

Acoustic: No positive findings of disturbance of this nerve were elicited.

Vestibular: There was no dizziness; the Romberg sign and gait were not tried.

Glossopharyngeal: There was some difficulty in swallowing, particularly during the preceding days, and the voice had changed in character. The aunt thought it was harsher than usual.

Vagus: The pulse was regular but slow. The palate was symmetrical. There had been considerable vomiting.

Spinal Accessory: The trapezius was of normal power on the right side, somewhat weak on the left.

Hypoglossal: There was no deviation of the tongue and no tremor.

Cerebrum.-Frontal: The patient had lately become very stupid and said herself that she did not take as much interest in things as formerly. At the time of examination she could scarcely be aroused. Precentral: There were no convulsions or twitchings. Postcentral: No disturbance of touch, pain or temperature sensitivity, muscle sense or sense of position was noted. Tem- 
poral: There were no hallucinations of smell or taste, no uncinate attacks, and no hemianopsia. Occipital: There were no hallucinations of light and no hemianopsia. Parietal: Astereognosis was not present.

Cerebellum.-There was suboccipital tenderness on both sides, possibly slightly greater on the left. There was some stiffness of the neck and flexion caused some pain. There was no nystagmus. The Romberg test and the gait were not tried, but there was a history of staggering to the left and inability to stand with the eyes closed, the patient falling to the left. There was marked hypotonicity on the left side, more marked in the upper extremity. Holmes' wrist sign was positive, as was Holmes' finger sign also. There was marked adiadokocinesis in the left hand. Muscle sense and sense of position seemed to be fairly normal. There was marked ataxia of the left upper and lower extremities on finger to finger, finger to nose and heel to shin tests. Caloric and rotation tests were not tried.

Reflexes.-The biceps, triceps and periosteal reflexes, knee jerks and ankle jerks were elicited, being greater on the left than on the right. The corneal, epigastric, abdominal, and plantar reflexes were present, but the left plantar was very sluggish.

Vasomotor: No vasomotor disturbance was observed.

Sphincters. -The control of these was good.

Roentgen-Ray Examination.-The convolutional impressions were increased throughout the skull. The sella was not well outlined. The frontal bone appeared irregularly thin, the parietal bones were thickened and the skull in this region was irregular in outline.

Operation.-Suboccipital exploration for presumed cerebellar tumor was performed by Dr. Harvey Cushing, Sept. 23, 1919, the anesthetic being ether.

The usual cross-bow incision was made. The suboccipital bone was much thinner on the left, though there were no patches of exceptional thinning. A wide area of bone was removed. There was an exceptionally deep bony septum projecting between the two hemispheres for a depth of about $1 \mathrm{~cm}$. Some difficulty was experienced in dislodging this median partition and in doing so the dura near the lower part of the field was slightly torn and cerebrospinal fluid escaped abundantly through the small opening. There being no further risk in incising the dura, this procedure disclosed two normal appearing hemispheres. It is possible that there may have been some wedging of the cerebellum into the foramen, though this was not extreme, and on pulling up the two hemispheres the calamus could be seen. The right hemisphere was larger and possibly more firm as though there might have been a tumor. An exploratory needle was inserted into each hemisphere to a depth of $5 \mathrm{~cm}$. without disclosing a lesion (possible cyst). The patient took the anesthetic well, and the wound was quite dry throughout. It was closed in layers, but just before the final closure a perforation was made through the pole of the left hemisphere and the needle was inserted into the ventricle, an abundance of fluicl being reached at a depth of $3 \mathrm{~cm}$., evidencing therefore an internal hydrocephalus.

Postoperative Course.-The patient made a good ether recovery. Five days after the operation she was much brighter; the headaches had been entirely relieved, but the ptosis of the right eyelid persisted.

The cast was removed October 3 and the stitches taken out. The wound healed in excellent approximation, but some fluid was under the incision line. 
Headaches and vomiting were completely relieved, and the patient thought that her vision was better, but there was no improvement in ability to use the left arm and leg.

The patient was up in a wheel chair October 5. Examination of the left fundus disclosed that the disk and the vessels over the disk were obscured by new tissue, the veins were tortuous, the disk was not elevated. The same conditions were noted in the right fundus, with small hemorrhage in the upper border of disk.

The patient was very well and happy until the morning of October 10 . While sitting up in a wheel chair she became dizzy and faint, was put back

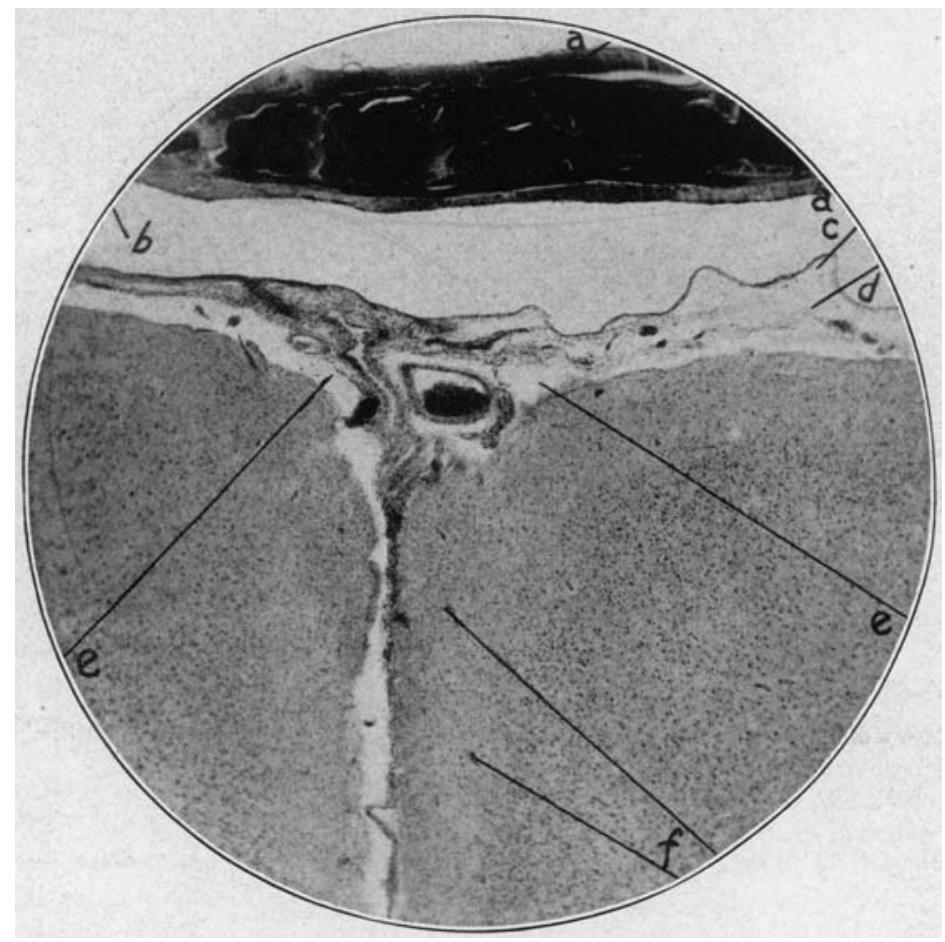

Fig. 1.-Transverse section from the motor area near the longitudinal sinus, the three membranes included. $A$, inner and outer layers of the dura, the cartilaginous mass between being very darkly stained and connective tissue strands dividing it being distinctly seen. $B$, subdural space. $C$, arachnoir membrane. $D$, subarachnoid space, greatly infiltrated, especially in the region of the sulci. E, so-called epicerebral space (probably an artefact, though some amorphous substance is seen within the space said to be the result of edema). $F$, small vessels. (Celloidin section, thionin stain, $\times 24$.)

to bed and recovered. After lunch she became faint and stupid and vomited. Lumbar puncture showed that the fluid was not under tension, and perfectly clear. About $6: 30$, the patient had a generalized convulsion. There were clonic movements of all the limbs beginning on the left side, but she did not lose bladder or rectal control. The respiration and heart rates continued normal. 
On the following day the patient had another convulsive attack about 3 a. m., followed by profuse perspiration. She was fairly bright and said her headache was better. October 16 , she was very dull all day and could not be induced to talk.

October 19, there was bilateral ptosis and bilateral downward and outward squint with paralysis of convergence, both more marked on the right. The right pupil was slightly larger than the left. On the left side the reflexes were slightly exaggerated with marked hypotonicity and ataxia. The decompressed area was full, but not especially tight. No sensory disturbance was elicited. The

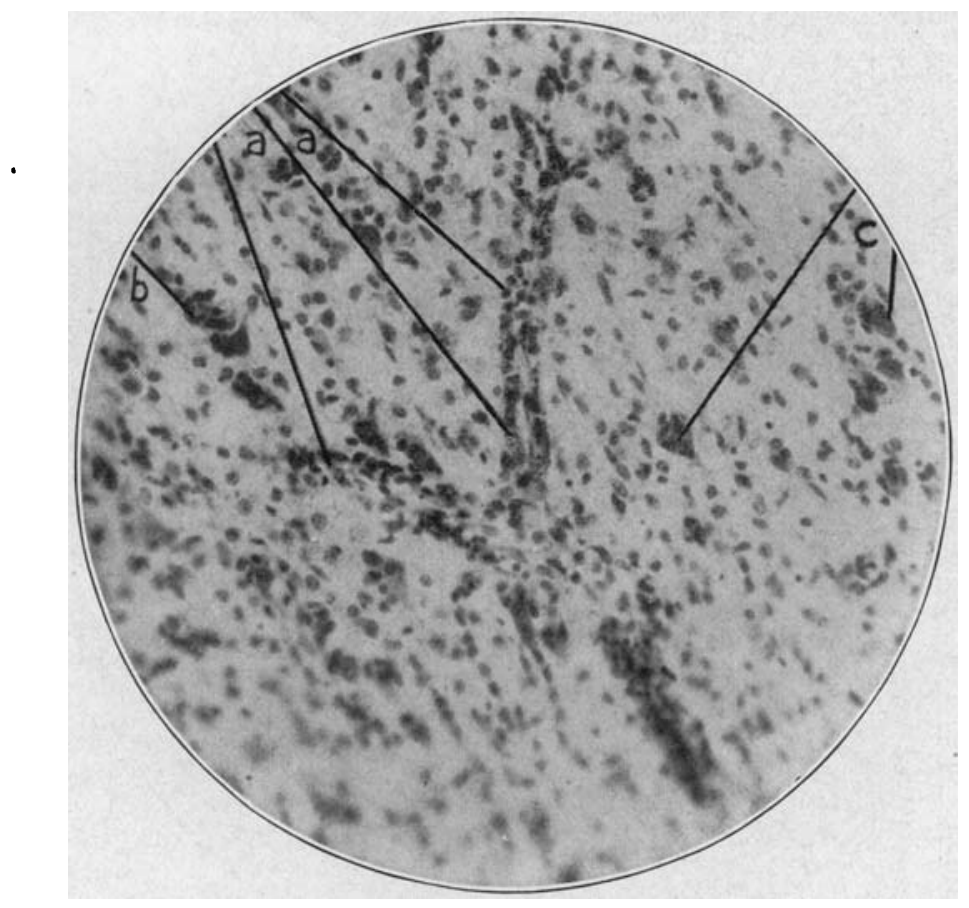

Fig. 2.-Section from the temporal lobe. The center of the picture is occupied by a branching vessel. The vessel walls appear to be infiltrated, but the numerous cells surrounding the branches are glia cells. (Use hand lens.) The rest of the picture is covered by a great number of ganglion cells and glia nuclei. Many of the former are in a state of neuronophagia $(B$ and $C$ ). $A$, glia wall. $B$, ganglion cell surrounded by eleven glia nuclei. $C$, two other ganglion cells invaded by glia cells. (Thionin stain, $\times 225$.) See also Figure 6.

Babinski reflex was negative. Both disks were very vascular, the veins were enlarged and tortuous and the disks elevated 3 diopters; large hemorrhages were noted in the periphery. The patient was usually very stupid. The convulsions began with twitching in the right eyelid.

This condition remained unchanged with some slight daily progression for the worse until the child's death, November 4, forty days after operation.

Presumptiz'e Diagnosis.-Basilar tumor (unverified) with hypdrocephalus. 


\section{PATHOLOGIC FINDINGS *}

Macroscopic.-The necropsy was limited to the brain, which was removed in its meninges after intracarotid injection of formalin. No macroscopic pathologic changes were present except slight hydrocephalus.

Microscopic.-Material: Blocks from the right frontal, motor, parietal, occipital, and temporal regions of the cerebral cortex, left cerebellar hemisphere, and pons, mid-brain, thalamus, and medulla were used. The material was all preserved in 10 per cent. formalin.

Methods: Celloidin, frozen and paraffin sections were stained by thionin, toluidin blue, van Giesen, Weigert's elastica stain, Alzheimer-Mann, Herxheimer's scarlet red stain, and Bielschowsky's silver method.

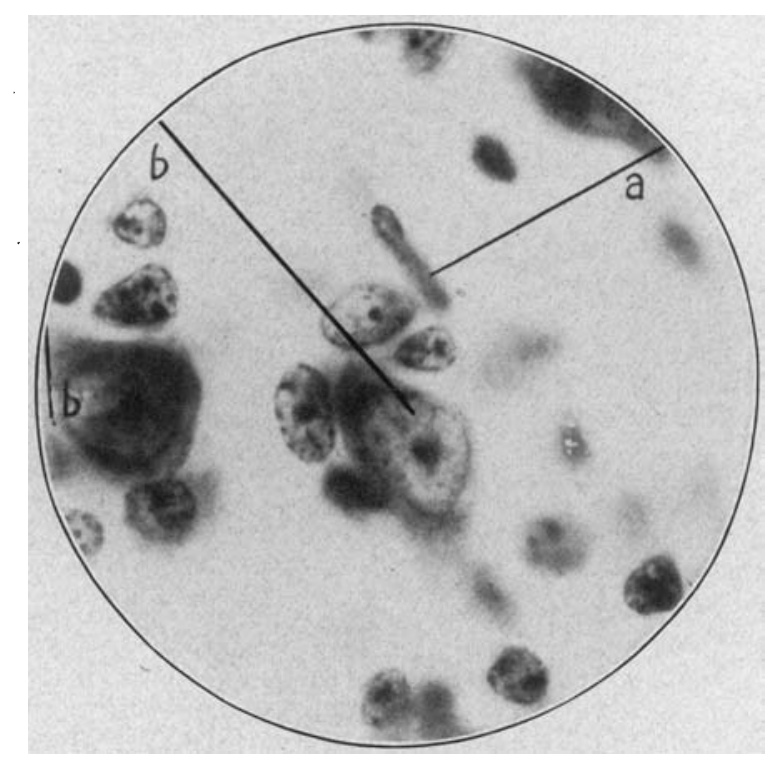

Fig. 3.-Section from the temporal lobe. $A$, rod-cell (Stäbchenzelle). $B$, two ganglion cells in a state of neuronophagia. The rest of the cellular elements are glia cells. (Thionin stain, $\times 1200$.)

A modification of the Alzheimer-Mann (methylblue-eosin) method gave very valuable pictures on formalin-fixed celloidin material. The following procedure was used:

1. Fix in 10 per cent. liquor formaldehydi.

2. Embed in celloidin; cut 15 microns or thinner, in 70 per cent. alcohol.

3. Wash in distilled water.

4. Transfer to aqueous solution of phosphomolybdic acid, from 1 per cent. to saturated, for from one to twelve hours.

5. Pass through two changes of distilled water into

* From the Pathologic Laboratory of the Cook County and Psychopathic Hospitals, Chicago. 
6. Mann's stain (eosin, 1; methyl blue, 1; distilled water, enough to make 100 ), for from one to twelve hours (preferably twelve).

7. Differentiate directly in 70 per cent. methyl alcohol; move constantly.

8. Transfer to 95 per cent. ethyl alcohol and mount on slide.

9. Add absolute ethyl alcohol on slide.

10. Xylol; Canada balsam (creosote may be used).

The stain comes off in the methyl alcohol in a regular fog and the methyl alcohol differentiation may be carried as far as desired. If left too long in the ethyl alcohol, the eosin will be lost, while the absolute ethyl alcohol also removes the celloidin. The latter contingency may be obviated by adding

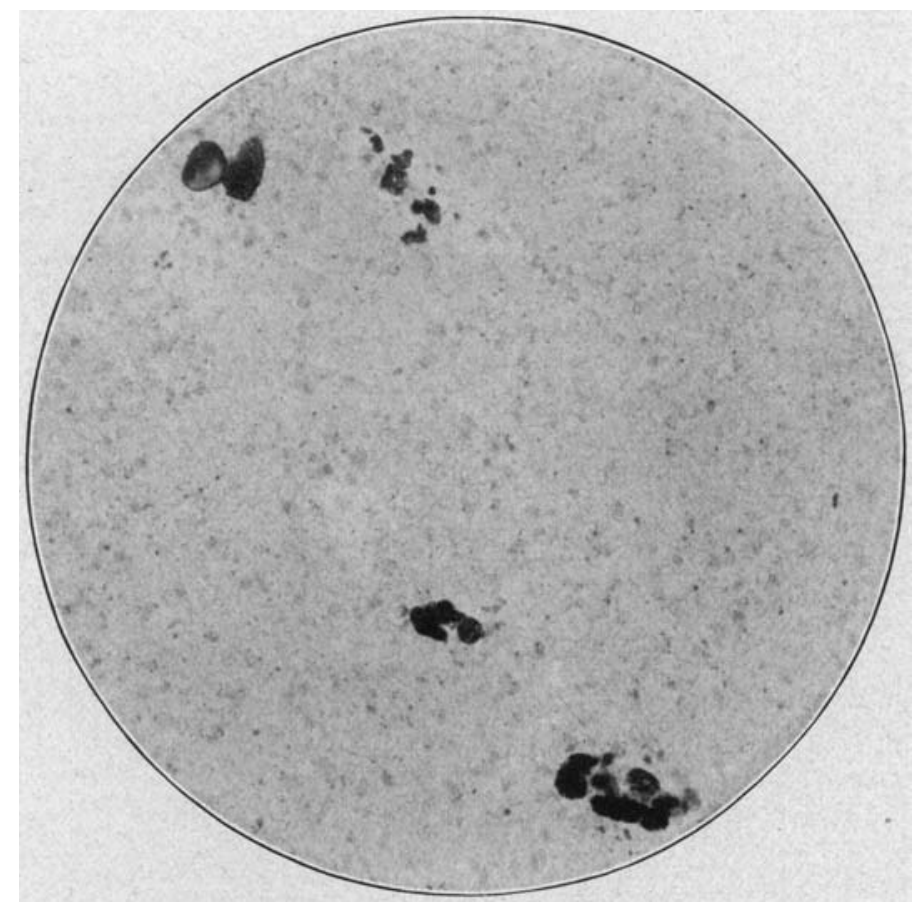

Fig. 4.-Section from the motor area. The perivascular spaces of the vessels are packed with fat (large dark globules). (Frozen section, Herxheimer's scarlet red stain, $X 225$.)

20 per cent. chloroform to the absolute alcohol. The mesodermal tissue, namely, the pia and vessels down to the finest capillaries, is stained a bright blue; the glia, violet to purple; the nuclear structures, dark red; the myelin, a bright pink, and the red blood corpuscles, a brilliant orange. The color contrasts are much less striking if examined by artificial light.

Meninges: Microscopically the dura showed no changes with the exception of some areas near the longitudinal sinus, consisting of almost structureless formations, containing here and there small lacunae filled each with a single cell (Figure 1). The nature of these masses was hard to determine. They were more or less uniformly stained by thionin, van Giesen, Alzheimer-Mann and Weigert's elastica stain, filled up the enlarged dural interspaces to which they were strictly confined. They resembled cartilage or newly formed bone. 
The enlarged subdural space was without cellular or other contents, which, however, were abundant in the pia-arachnoid, subpial (epicerebral) and subarachnoid spaces (Figure 1). The pia-arachnoid cellular infiltration was present everywhere, but was most marked around the medulla, while over the parietal lobe the pia appeared scarcely infiltrated, but edematous.

The localization of the infiltrative elements was best studied in specimens stained by the modified Mann method, and their character was most readily determinel in thionin stained specimens. These elements included lymphocytes, plasma cells, macrophages, rod cells, polyblasts, and fibroblasts. Most numerous were plasma cells and lymphocytes, mixed with erythrocytes.

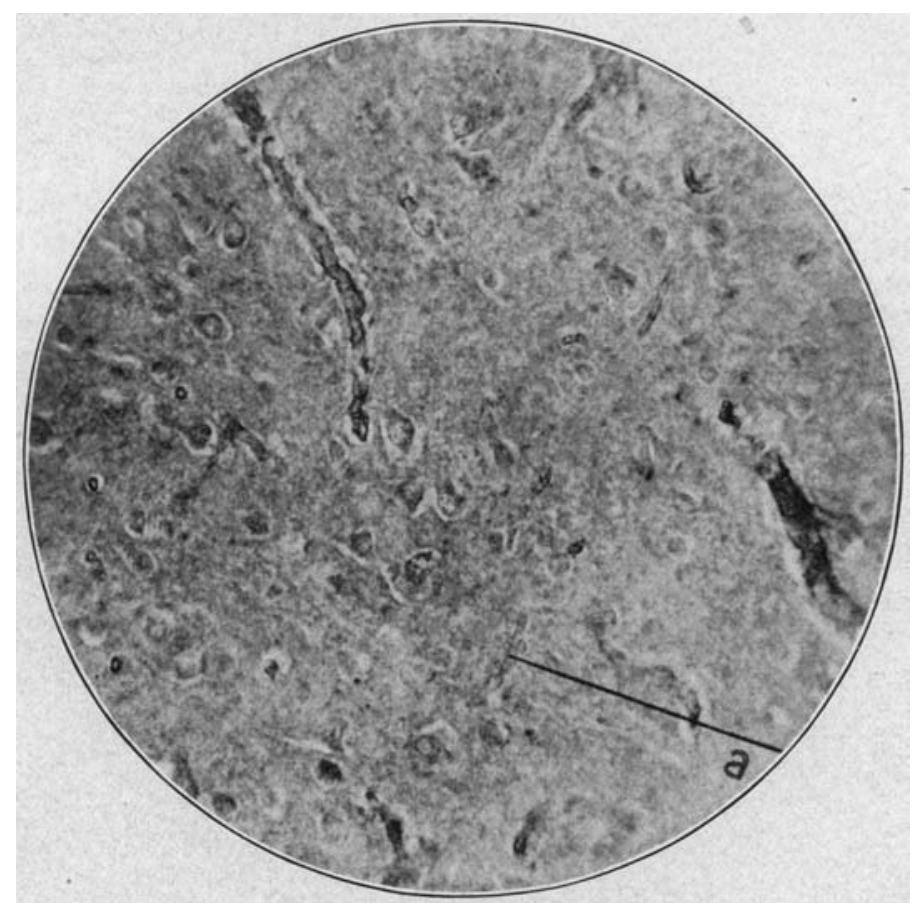

Fig. 5.-Section from the motor area. The field is occupied by a great number of vessels, the majority of which are well developed. In the stained specimen are seen a great number of newly formed vessels, one of which is seen at $A$. (Weigert's elastica stain, $\times 225$.)

In thionin stained specimens, the lymphocytes appeared as small, round, heavily stained, often almost homogeneous nuclei, with no visible cytoplasm. The erythrocytes were cup shaped, pale green bodies without nuclei. Plasma cells were quite numerous, their eccentric nuclei with spokelike chromatin and metachromatically stained cytoplasm with a clear halo alongside the nucleus heing clearly discernible. In addition, a considerable number of macrophages were seen packed with blood pigment, which was also scattered freely in the distended meshes of the pia-arachnoid.

The foregoing cellular elements (lymphocytes, plasma cells, erythrocytes, and macrophages) were mixed with so-called mesothelial cells, which are large, rouncl or oblong nuclei containing a scanty amount of chromatin and 
hardly visible cytoplasm. Somewhat similar were many other nuclei with protoplasm streaming away from either end which may be classified as fibroblasts. Polyblasts with pale horseshoe-shaped nuclei, surrounded with rich cytoplasm, were everywhere in evidence, while around the vessel walls were seen sausage-shaped, oblong nuclei without visible cytoplasm, but rich in chromatin, so-called rod cells (Stäbchenzellen). Polymorphonuclear and cribriform cells (Gitterzellen) were not found.

The vessels of the pia-arachnoid appeared to be distended, but manifested no infiltrative nor other changes.

Cortex: In the cortex, parenchymatous and interstitial changes were in evidence, being most pronounced in the parietal and temporal lobes of the

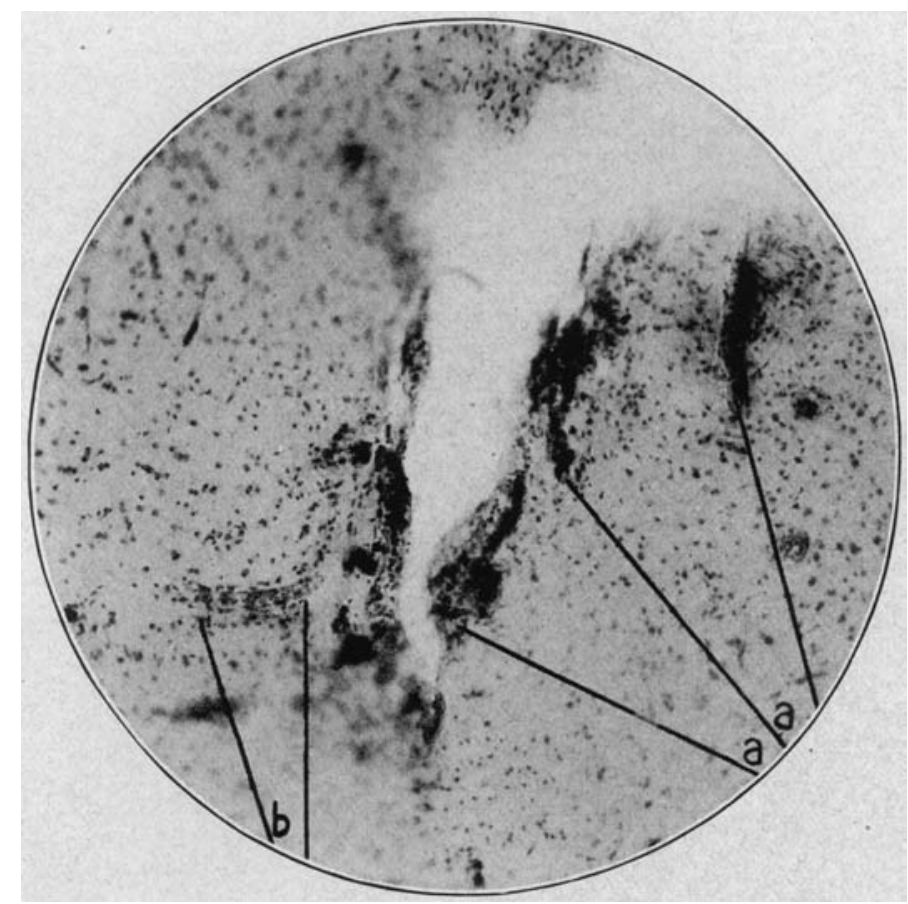

Fig. 6.-Section from the parietal lobe. Some vessels (A) greatly engorged and infiltrated. Other vessels $(B)$ are not infiltrated, but show a beautiful row of glia cells forming a wall. (Thionin stain, $\times 82$.)

cerebrum; the cerebellar cortex was relatively slightly involved. The parenchymatous changes predominated, and showed only in the ganglion cells, varying in degree from those of Nissl's acute cell disease to total destruction of the cells. Throughout the cortex, the majority of the ganglion cells were very poor in tigroid substance, and the nuclei were rather pale and poor in chromatin. Especially pronounced were these changes in the deeper layers of the cortex, where cell after cell could be seen surrounded by from three to ten robust glia cells (satellitosis). Though present throughout the deeper cortical regions, the satellitosis was especially marked in the parietal lobe, and attained its maximum in the temporal lobe, where it reached to the outermost layers of the 


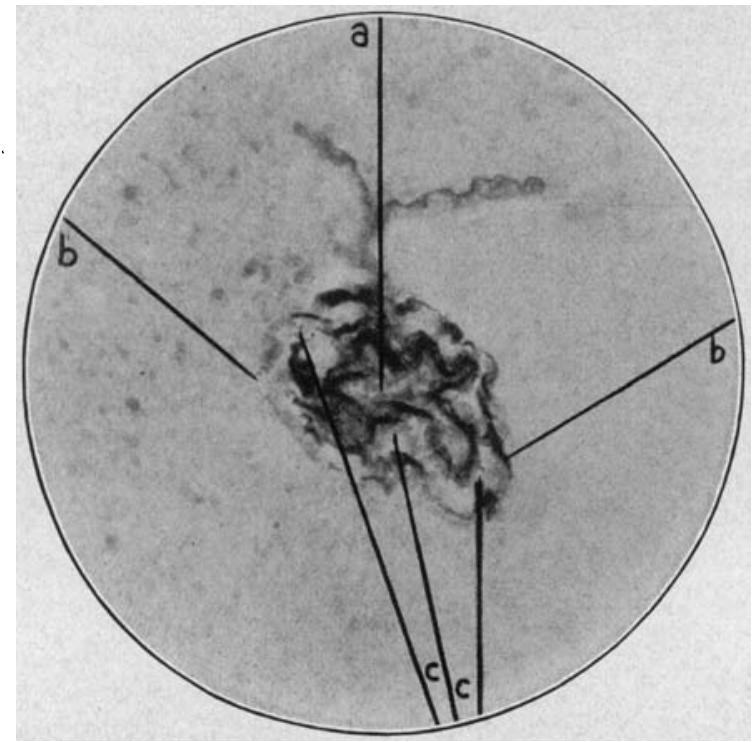

Fig. 7.-Small vein from subcortical area of temporal lobe showing the perivascular space of Virchow-Robin. It contains cellular elements which are not very distinct in the photograph. $A$, lumen. $B$, adventitia. $C$, perivascular space of Virchow-Robin. (Modified Mann's methylblue-eosin stain, celloidin section, $\times 230$.)

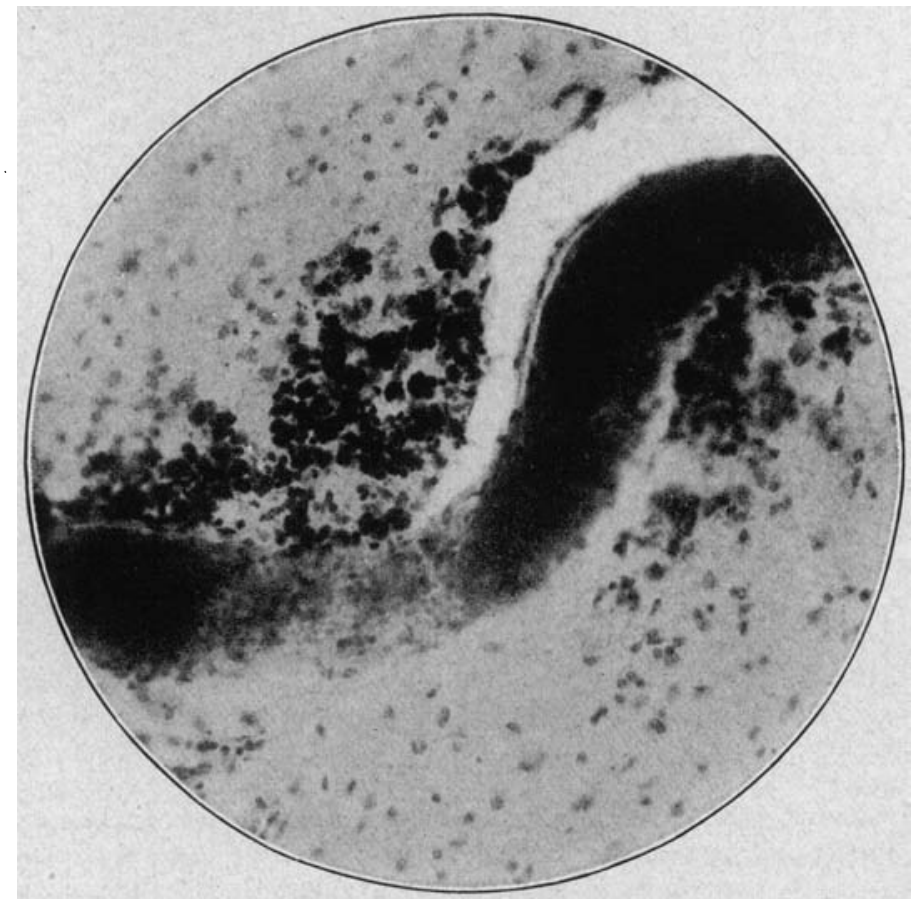

Fig. 8.-Engorged vein from subcortical region of parietal lobe surrounded by an enormous number of macrophages packed with blood pigment (black globules). (Thionin stain, $\times 225$.) 
cortex (Figure 2). In these areas, the glia cells not only clustered around but actually invaded the bodies of the ganglion cells (neuronophagia) (Figure 3 ). The dendrites were shrunken, heavily stained, without Nissl substance and in some places the whole cell was reduced to an amorphous granular mass. Herxheimer specimens showed that these dying cells were packed with fat, especially at the base.

The glia everywhere showed proliferative changes, chiefly in the form of increase in the number and size of cells and chromatin content of the nuclei. Many of the glia cells had an appreciable amount of cytoplasm (protoplasmic glia cells). Around some vessels, especially those where hemorrhage had occurred, a distinct glia wall (Figure 2) was formed-rows of glia cells and proliferated glia fibers. Regressive changes, such as ameboid glia cells, Füllkörperchen, etc., were absent. In the regions where neuronophagia was intense,

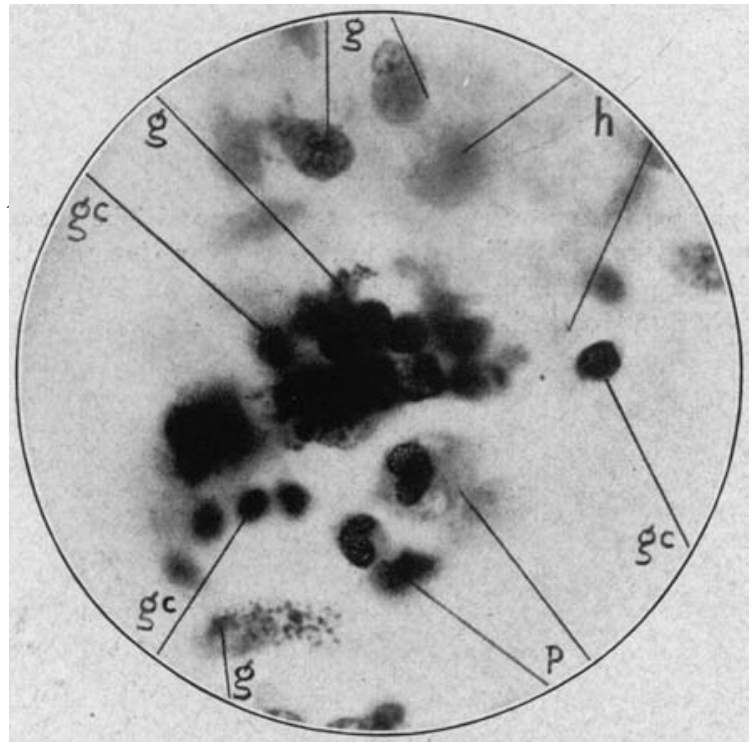

Fig. 9.-Hemorrhage, evidently of recent date. The majority of the g.ia cells $(G)$ are packed with granules of hemosiderin. $H$, hemorrhagic focus. $G$, glia cells containing blood pigment. $G C$, glia cells, out of focus, forming a dense nest in the center and an arch of four underneath. $P$, polyblasts, the nuclei appearing dark because they are out of focus. (Thionin stain, $\times 1000$.)

the glia cells could be seen to contain considerable fat, which was evidently transported to the blood vessels, where fat could be demonstrated in the adventitial cells. Vessels surrounded by such fat-laden cells were seen in all parts of the cortex (Figure 4), but were most numerous in the temporal lobe.

Interstitial changes in the cortex were not marked, aside from excessive vascularization. Some areas showed an abundance of vessels and capillaries, many of which were very thin and empty, with only a few endothelial cells (Figure 5). Specimens stained with Weigert's elastica stain showed a well developed elastic membrane, sometimes, but very seldom, split into several layers. Inflammatory phenomena were mild, consisting of slight dilatation of the Virchow-Robin spaces, exclusively filled with lymphocytes (Figure 6). 
The interstitial changes were especially marked in the subcortical regions. Thus in the temporal lobe there was well developed perivascular infiltration, chiefly with lymphocytes, but numerous plasma cells were also present. Specimens stained with the modified Mann method showed especially well that these infiltrative cells were confined to the Virchow-Robin spaces (Figure 7). Occasionally throughout the subcortical region, but notably in the parietal lobe, a vessel could be seen surrounded by a mass of macrophages engorged with blood pigment (Figure 8), and around these marked glia fiber proliferation. The area shown in Figure 8 is evidently the site of an old hemorrhage and the macrophages are heavily laden with the products of erythrocyte destruction (hemosiderin), but at other places fresher hemorrhages may be found where minute granules can be seen in the masses of glia cells (Fig. 9).

Brain Stem: In the brain stem, the changes described in the foregoing were much less pronounced. In the thalamus was to be found slight perivascular infiltration with lymphocytes and plasma cells. Excessive vascularization was present with newly formed capillaries. Hemorrhages, evidently fresh, without reactive phenomena, were scattered about. Nowhere were there any signs of nerve fiber destruction. Occasionally protoplasmic glia cells were seen, but satellitosis and neuronophagia were practically absent. In the substantia nigra, pons, peduncles, and medulla the changes were similar, but still less pronounced, consisting chiefly of increased vascularity, hyperemia, and occasional fresh hemorrhages. Myelophages, cribriform cells (Gitterzellen) and other pathologic glia changes associated with nerve fiber destruction were totally lacking.

\section{COMMENT}

The foregoing combination of interstitial and parenchymatous changes prove that we are dealing here with a case of hemorrhagic leptomeningo-encephalitis, which clinically presented a clear-cut picture of tumor of the left cerebellar hemisphere. More than any case heretofore recorded it deserves the name of "pseudotumor."

There are some extraneous factors in this case which seem to invalidate the diagnosis. For instance, the third nerve palsy was noted as an unusual finding, but was disregarded, because the cerebellar symptomatology was so pronounced, and also because previously it had been seen in cases proved at operation to be cerebellar tumor. Again, the symptoms were stated to follow an attack of influenza, but the father also dated the squint from ivy poisoning! It may be objected that some of the pathologic findings were the result of operative trauma. This is untenable, for the subpial, parenchymatous, and other changes (neuronophagia, perivascular infiltration, etc.) were distinctly of inflammatory infectious nature. Also the pathologic changes were much less evident in the cerebellum at the site of the operation than in the temporal and parietal lobes of the cerebrum, remote from the operative field.

The combination of parenchmatous and interstitial changes will be found in any type of encephalitis, be it dementia paralytica, trypanosomiasis, lethargic encephalitis or poliomyelitis. Yet the present case 
greatly differs from the foregoing types, especially from lethargic encephalitis. The presence of antemortem hemorrhages, the lack of intensive perivascular infiltrations, and what is more important, the absence of lesions in the substantia nigra, are sufficient to rule out the latter type.

The presence of antemortem hemorrhages might indicate that this was an instance of encephalitis caused by influenza, but in the absence of any reliable histopathologic reports of influenzal encephalitis it would be rash to make such a diagnosis in the present case. The majority of authors ${ }^{10}$ (Schroeder, Redlich, and Lhermitte ${ }^{11}$ ) do not consider the cerebral lesions found in influenza as an encephalitis at all.

In view of the widespread involvement of the brain in cases of meningo-encephalitis, it is not surprising that it is difficult clinically to localize the lesion, nor that striking pathologic lesions should be found in areas not indicated by the clinical findings. In the case reported here the pathologic changes in the cerebellum were adequate to account for the cerebellar symptoms but were overshadowed by more striking changes in the cerebrum.

\section{CONCLUSIONS}

1. A case simulating a tumor of the left cerebellar hemisphere proved on microscopic examination to be a meningo-encephalitis Macroscopically the brain showed only slight hydrocephalus.

2. Cases of meningo-encephalitis may run the clinical course of a tumor of the brain even with definite localizing signs but without definite pathologic localization.

3. From a consideration of the cases properly examined, it is certain that no clinical 'or pathologic entity exists which deserves to be dignified by the term "pseudotumor cerebri."

4. The term "pseudotumor cerebri," if used at all, should be restricted to purposes of clinical classification without attributing to it any etiologic or pathologic significance whatever.

I am greatly indebted to Dr. George B. Hassin for constant advice and criticism, and to Dr. Harvey Cushing for permission to study this case.

10. See Bassoe, Peter, and Hassin, G. B.: Contribution to the Histopathology of Epidemic ("Lethargic") Encephalitis, Arch. Neurol. and Psych. 2:40, 1919.

11. Lhermitte, J.: L'encéphalite léthargique, Ann. de med. 6:306, 1919. 